\title{
Models of Functional Heterogeneity and Targeting Strategies for Cancer Stem Cells
}

Joan Lee, BHSc Student [1]*, Sai Gayathri Metla, BHSc Student [1], Chaoqun Xu, BHSc Student [1]

All authors contributed equally.

[1] Faculty of Health Sciences, McMaster University, Hamilton, Ontario, Canada L8S 4L9

*Corresponding Author: leet53@mcmaster.ca

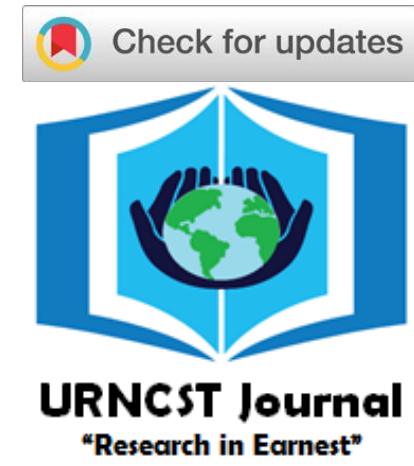

\begin{abstract}
Introduction: Functional heterogeneity, defined as variations between and within tumours, is the underlying cause for malignant tumour processes such as tumour progression, metastasis and treatment resistance. In particular, cancer stem cells (CSCs) could be important contributors to functional heterogeneity within tumours, as CSCs can differentiate into different tumorous cells. This study aims to identify models for the genesis of functional heterogeneity among cancer cells and strategies for targeting CSCs.

Methods: Using an integrated review process, various models for functional heterogeneity genesis in cancer and cancer stem cell treatments were explored. Papers that explicitly focused on either explaining a model for the genesis of functional heterogeneity in cancer or on describing targeting strategies for CSCs were included. To conduct our search the following databases were used: PubMed, OVID (Medline), and Web of Science.

Results: Several prominent models for genesis of cancer functional heterogeneity were identified, including the hierarchy model, stochastic model, and plasticity model. There is no definitive model as different types of cancer may follow different models of functional heterogeneity. However, multiple models suggest that CSCs, tumor cells with acquired or innate multipotency, are responsible for enhancing tumour progression. Hence, many therapeutic methods have been explored to target CSCs including: interfering with signalling pathways, targeting biomarkers, exerting transcriptional control, damaging quiescence, disrupting the microenvironment and immunotherapy.

Discussion: This study identified a gap in current literature to be the lack of clinical studies, with the majority of experiments being conducted on mice models or in vitro. As such the applicability of the findings on a human in vivo level are unclear. Strengths of this paper include the extensive scope of literature reviewed, while limitations include the lack of a quality assessment stage.

Conclusion: This study suggests that CSCs are involved in the development of functional heterogeneity in tumours and identifies some preliminary strategies to target them. However, more clinical trials are needed to further validate current proposed treatments. By developing CSC-specific therapies, functional heterogeneity amongst cancer cells can be decreased, which will prevent cancer cells from continuing to progress. As a result, these treatments will be more likely to effectively treat cancer.
\end{abstract}

Keywords: functional heterogeneity; cancer stem cells; hierarchy model; stochastic model; plasticity model

\section{Introduction}

Tumours are composed of varying cell populations exhibiting genetic and functional heterogeneity [1]. Tumour heterogeneity has been identified at molecular and genetic levels, even amongst cancer cells that appear identical [1,2]. Variations in tumours can be found between tumours in different tissues, tumours in different patients, and tumours in the same patient [3]. This is known as intertumoural heterogeneity. Additionally, variations can also be found within a single tumour, which is called intratumoural heterogeneity [3]. In particular, intratumoural heterogeneity is problematic as it plays a role in causing neoplastic lesions which causes tumour spread, complicating the prognosis and treatment of cancer, as well as potentially leading to relapse following treatment [3].

Cancer stem cells (CSCs) are a small group of tumour cells that are postulated to be important contributors to intratumoural heterogeneity [1]. Much like embryonic stem cells or adult stem cells, CSCs are cells that maintain the ability to differentiate into diverse lineages, self-renew, metastasize, resist treatment, and maintain suitable microenvironments [4]. Unlike regular stem cells, CSCs are not subject to the usual controls that limit cell growth [3]. The exact traits and mechanisms by which CSCs survive 
UNDERGRADUATE RESEARCH IN NATURAL AND CLINICAL SCIENCE AND TECHNOLOGY (URNCST) JOURNAL Read more URNCST Journal articles and submit your own today at: https://www.urncst.com

and function in cancer heterogeneity remain to be established $[2,4,5]$.

The factors that lead to the formation of heterogeneity within tumours remains to be elucidated. Many different models have been suggested to explain this phenomenon, with the predominant models being the hierarchy model, the stochastic model and the plasticity model $[2,3]$.

The hierarchy model proposes that tumours are composed of cells displaying divergent lineage, with a small fraction of tumour cells, CSCs, having the ability to selfrenew and differentiate [2]. These CSCs are considered to be at the apex of the tumour cell pyramid. On the other hand, the stochastic model argues that all tumour cells are biologically homogeneous, and that their behaviours are influenced by intrinsic and extrinsic factors which randomly result in new functional characteristics among cells [6]. Lastly, the plasticity model is founded on the idea that cancer cells are in a constantly evolving state [6]. This dynamic process may increase or decrease the expression of CSC markers on a cell at any given moment. Due to their plasticity, any cell may adjust to unfavourable environmental conditions to hinder cancer treatment [7].

There is still currently a high degree of uncertainty regarding the mechanism through which functional heterogeneity in tumours is generated [1]. By enhancing the understanding of the different types of models, researchers and clinicians will be able to better target their attention towards relevant biological processes. Consequently, they will be able to improve current diagnosis and treatment options to allow for more accurate prognosis and effective therapeutics. Additionally, while great progress has been made in developing therapeutics that target CSC's, none of them have been successful as of date, and as such, additional research in this area is required. Using an integrative review method, this study aims to discuss the aforementioned models for the genesis of heterogeneity in cancer and highlight potential strategies for targeting CSCs by analyzing the existing available literature.

\section{Methods}

Integrative reviews have been found to be effective at gathering a wide range of perspectives on topics of interest [8]. This approach is well suited for reviewing a diverse range of studies and for providing a comprehensive understanding of current literature.

Literature Search and Data Evaluation

The search engines OVID (Medline), PubMed and Web of Science were used. Three researchers (CX, SM, JL) each conducted two independent searches in one database each. Purposive sampling was then used by each researcher to independently select publications for full-text review based on screening of titles and abstracts. Disagreements were resolved through discussion and consensus was reached after careful assessment of the articles.

Lee et al. | URNCST Journal (2021): Volume 5, Issue 3

DOI Link: https://doi.org/10.26685/urncst.217
The first search utilized the keywords (cancer OR tumor OR tumour) AND (heterogeneity) AND (functional OR phenotypic)) AND (model OR hierarchy OR stochastic OR plasticity). The second search used the keywords (cancer OR tumor OR tumour) AND (heterogeneity AND (functional OR phenotypic)) AND (Stem cells OR therapy OR target strategy OR treatment).

The inclusion criteria used to select articles included: (1) written in English, (2) published in peer-reviewed journals between January 2010 to September 2020 and (3) focused on either explicitly explaining the hierarchy model, the stochastic model, or the plasticity model or on describing targeting strategies for CSCs. The focus on published, peer-reviewed literature was to ensure that selected publications would be of high quality. The criteria for the publication time was set to ensure that the review would reflect current knowledge on the topic. Unpublished manuscripts such as abstracts or dissertations were excluded.

Upon applying inclusion criteria, 23,341 publications were returned. From this, studies that focused mainly on explaining one of the models or on explaining the targeting strategies were selected through title and abstract screening. A balance between the number of papers describing each model was maintained. Through this screening process, a total of 20 publications were selected at the author's discretion and these studies formed the basis of this integrative literature review.

\section{Data Analysis}

Data analysis was conducted using established methods. The data analysis consisted of four stages: data reduction, data display, data comparison and verification [8]. A predefined data sheet was used for data reduction and data display. The following data was extracted for each study: year of publication, heterogeneity genesis model descriptions, as well as targeting strategies for CSC and their descriptions. Afterwards, data comparison was conducted by the three investigators individually. During this stage common themes within the articles were identified, and information from the articles were aggregated. Finally, in the verification stage all three authors discussed their identified findings and compared their results to the original articles, reaching a consensus on what the major findings of this integrative review would be.

\section{Results}

Functional Heterogeneity Models

\section{The Hierarchy Model}

The hierarchy model, sometimes referred to as the cancer stem cell model, is characterized by its focus on a subpopulation of cells, named CSCs, which are postulated to have an enhanced capacity for self-renewal and differentiation [9]. All cancer cells are considered to be arranged in a pyramidal shape, shown in Figure 1, with the 
CSCs at the apex $[3,10]$. The proportion of CSCs in a population of cancer cells is different in every tumour [1]. Through the production of large heterogeneous populations of tumour cells, CSCs can initiate new tumours, attack new tissues, promote disease progression, and resist treatment [11]. In essence, the hierarchy model proposes that tumour growth and disease metastasis are driven by a predefined minority of tumorigenic cells, with other cancer cells having little contribution to this process [11].

As benign tumours progress to carcinomas, the hierarchy becomes shallower, with a denser population of CSCs [3]. New mutations constantly arise in cancer cells thus creating different characteristics for cells within the same type of tumour [12]. In non-CSCs, acquired functional changes cannot be passed on to the next generation of cells [12]. Conversely, if CSCs acquire a mutation that influences the cells' phenotype and function, it can readily pass down the mutation $[12,13]$. This model accounts for the functional heterogeneity seen within tumours and its ability to metastasize.

The origin of these CSCs is uncertain. Traditionally, scientists hypothesize that normal tissue stem cells can give rise to CSCs upon somatic changes [2]. Recently, studies have suggested that a pool of intermediary cells, called "transient amplifying cells", are mitotically active and accumulate in mutations to dedifferentiate and sustain the CSC pool [12]. Posing more barriers to treatment, the CSC property can be enhanced by radiation, acting as a barrier to any radiation-related therapy [5,9].

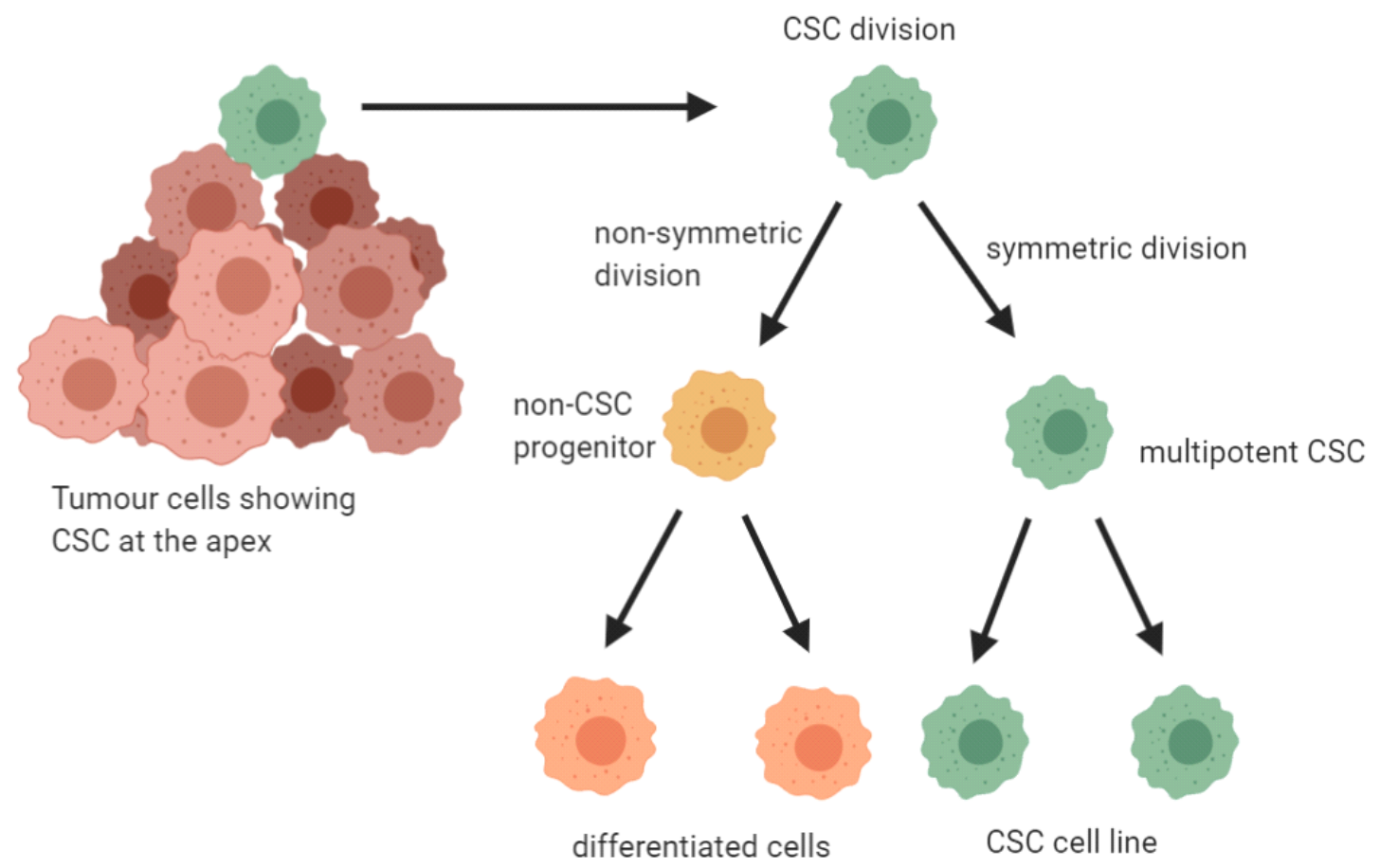

Figure 1. Hierarchy model. CSCs account for a small portion of tumour cells. They can undergo symmetric division to maintain the renewable and multipotent CSC line, as well as undergo non-symmetric division to form new differentiated cells.

\section{The Stochastic Model}

The stochastic, or clonal evolution, model was first proposed in 1976 [14]. This model suggests that the development of heterogeneity within tumours is due to evolutionary selection [15]. Figure 2 illustrates the processes involved. This model posits that all cells within a tumour have the potential to gain epigenetic or genetic mutations. Afterwards, if their environment favours their growth, they will be able to survive and proliferate $[11,15]$. A key characteristic that differentiates this model is the stochastic component, as every cell in the tumour can potentially acquire the mutations necessary to become metastatic or to gain other CSC-like properties [15]. In other words, tumour progression is not driven by a subset of pre-specified cancer cells, but rather, by continued selection of the most effective and resistant cells that arise through random mutations [15].

Epigenetic and genetic mutations are caused by a variety of intrinsic and extrinsic factors such as levels of transcription factors and the cell's microenvironment respectively [13]. The stochastic nature of these factors leads to heterogeneity in the various cancer cell's characteristics. 


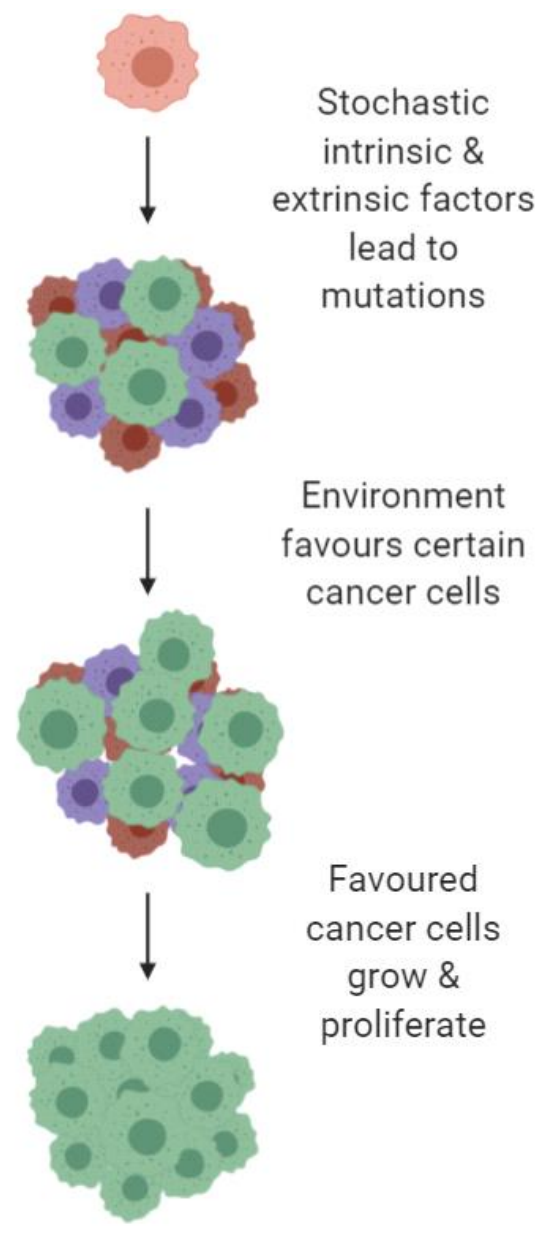

Figure 2. Stochastic model. Any cancer cells can develop the mutations necessary, based on evolutionary selection, to develop functional heterogeneity in cancer.

\section{The Plasticity Model}

Some researchers believe that the stochastic and hierarchy models are not mutually exclusive [3]. From this idea the plasticity model was devised which interconnects the two models [3]. The main idea behind this model is that cancer cells have cellular plasticity meaning that they can interconvert between stem cells and various differentiated states, see Figure 3 [3].

Tumours may be composed of CSCs that share the same ancestry but are genetically distinct [11]. The CSCs, with their self-renewal abilities, will persist and accumulate the epigenetic and genetic changes needed for cancer initiation and progression [11]. Through this process, the CSCs are proposed to continue to proliferate and create both more differentiated, non-tumorigenic cells and new cancer stem cells [11].

Recent studies have shown that some cells can readily switch between tumorigenic and non-tumorigenic states in the presence of certain stimuli and endogenous transcription factors [11]. The Weinberg group identified a subpopulation that can switch from CSCs to non-CSCs, supporting the plasticity model [11]. Their study demonstrated that plasticity is enabled by a transcription factor, ZEB1, and various other microenvironment stimuli [11].

Plasticity has specifically been found to play a role in breast cancer [7]. Breast cancer CSCs can be distinctly identified as being mesenchymal-like or epithelial like [7]. They have differences in proliferation, invasiveness, and localization. There is evidence that mesenchymal state cells are better in forming tumours compared to corresponding epithelial like cells [7]. The conversion of cells between these two states increases their invasion and metastasis capacity and contributes to increased difficulty in eradicating tumours [7].

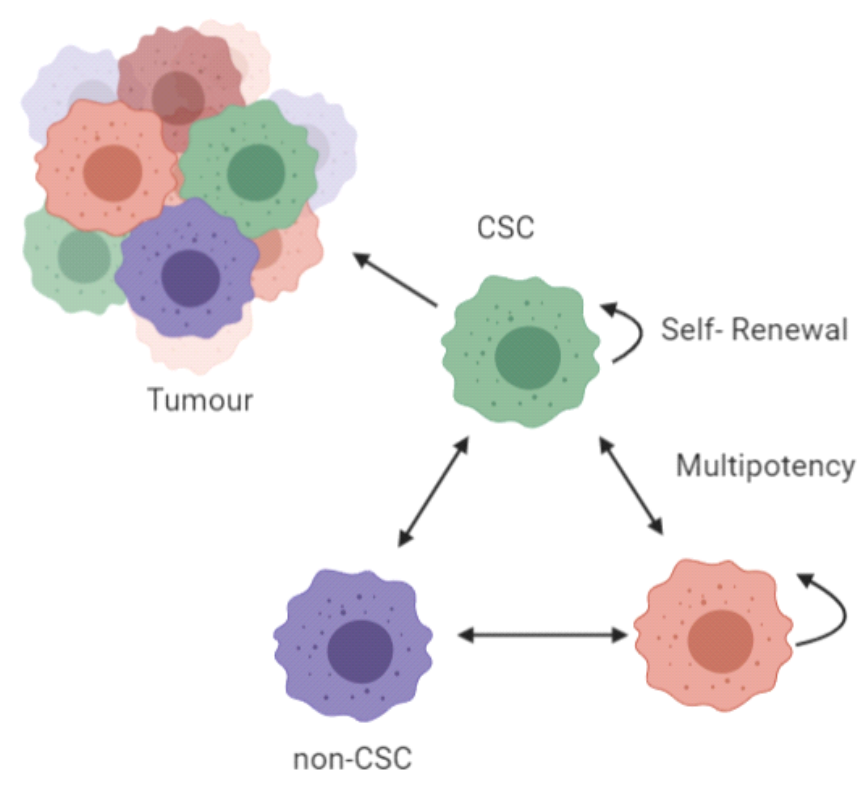

Figure 3. Plasticity Model. CSCs are able to proliferate and create more differentiated non-tumorigenic cells as well as stem cells. Cells can interconvert between various differentiated states.

\section{CSCs}

CSCs are a subset of tumour cells that have the ability to self-renew, differentiate, evade therapies and metastasize [15]. Akin to normal stem cells, CSCs have the ability to produce more stem cells and to differentiate into specialized cells [3]. This ability to differentiate allows for the generation of new characteristics in the cancer cell population, contributing to the heterogeneity within the tumour [9]. They are also able to evade many common therapies due to their quiescence, which is a state where cells enter into reversible growth arrest and can return to cellular proliferation under favourable growth conditions [15].

Quiescence is a state in which the cell is inactive. During their dormancy, CSCs maintain the ability to acquire additional mutations, in order to survive in a new 
UNDERGRADUATE RESEARCH IN NATURAL AND CLINICAL SCIENCE AND TECHNOLOGY (URNCST) JOURNAL Read more URNCST Journal articles and submit your own today at: https://www.urncst.com

environment, initiate metastasis, and become resistant to cancer therapy [15]. Therefore, traditional treatments, such as chemotherapy, which employ antiproliferative methods and can only damage cancer cells that are currently active and dividing [15]. Other factors within CSCs such as increased drug efflux rates, more efficient DNA repair and a protective microenvironment can also lead to their intrinsic resistance against cancer therapies [15]. Finally, CSCs also contribute to tumour metastasis through migration, although the exact mechanisms have not yet been determined [11]. However, it has been posited that they become mobile either by undergoing epithelialmesenchymal transitions or by acquiring facilitation from their microenvironment [11].

CSCs are found in tumour niches, or specialized microenvironments, which are made from a complex network of cells, including vascular, endothelial, and inflammatory cells, extracellular matrix and secreted factors [11]. This niche plays a critical role in the plasticity and functionality of CSCs by generating new CSCs, promoting growth, maintaining CSC-like properties, providing therapeutic resistance and initiating metastasis [11]. For example, the perivascular microenvironment specifically maintains the ability of CSCs in glioblastoma, a type of aggressive cancer in the brain and spinal cord, to metastasize [16].

Due to the critical role that CSCs play in tumour malignancy, it is important to target them during cancer treatment [15]. When targeting CSCs, a few things should be taken into consideration. First, all CSC subsets within the tumour need to be targeted to prevent a relapse [15]. Next, CSC plasticity induced by the microenvironment may impact the effectiveness of the treatment, as new CSCs could come from non-CSCs that escaped the implemented therapy [17]. As such, multiple therapies may have to be combined to ensure optimal effectiveness.

\section{$\underline{\text { Targeting Strategies }}$}

Signalling pathways

Certain signalling pathways are involved in the regulation of CSCs. For instance, the Hedgehog (Hh) pathway is active during the embryonic period and is critical in regulating the development of the neural tube and skeleton $[5,12,18]$. The Hh pathway has a diverse array of outcomes and is activated differently in various types of cancers. It drives tumour development, promotes tumour growth, and regulates remaining cancer cells following therapy [18]. There are higher levels of $\mathrm{Hh}$ signalling components found in cancer cells, and this helps to enhance tumour growth [5]. Research has shown that using antagonists such as cyclopamine can inhibit this pathway, and lead to depletion of CSCs [18].

Next, the Notch signalling pathway, activated by ligand-receptor binding on Notch receptors, is important for stem cell proliferation, differentiation, and apoptosis $[5,12,15,18]$. Different tumours express different Notch receptors and ligands, thus the Notch pathway can function as both an oncogene and a tumour suppressor depending on the cell type [18]. The function of the Notch pathway is determined by its microenvironment [18]. Abnormally hyperactive Notch signaling pathway has been observed in many cancer types, such as leukemia, glioblastoma, breast cancer, lung cancer, ovarian cancer, pancreatic cancer, and colon cancer [18]. There are presently three major clinical methods used to inhibit Notch signalling: secretase inhibition using the $\mathrm{\gamma}$-secretase inhibitor (GSI), monoclonal antibodies, and combination therapy [18].

The Wnt signalling pathway is involved in proliferation, differentiation, survival and apoptosis $[5,12,15]$. The Wnt signaling pathway is associated with tumour development in breast cancer, ovarian cancer, squamous cell cancer, colon cancer, prostate cancer and lung cancer [18]. There are currently two categories of Wnt pathway inhibitors [18]. Firstly, small molecule inhibitors, such as nonsteroidal anti-inflammatory drugs (NSAIDs) and molecular targeted agents like the CBP-B-catenin antagonist. The second is biologic inhibitors like antibodies and siRNA. The majority of Wnt inhibitors are in preclinical testing [18].

Although targeting CSC signalling pathways can be an effective therapeutic strategy there are drawbacks. The pathways that are targeted are not exclusive to CSCs, rather, they are shared with normal cells [18]. As such, the threshold for how much a signalling pathway can be tampered with must be determined to prevent destruction of healthy cells and prevent subsequent adverse side effects [18]. It is also unlikely that targeting one signalling pathway will be effective in eliminating all CSCs in any tumour given their plasticity and diverse genetics.

\section{Biomarkers}

Another prominent strategy for targeting CSCs is the development of monoclonal antibodies (mAbs) that target specific surface biomarkers that are differentially expressed across normal stem cells and CSCs $[13,19]$. For this type of therapy, ensuring that the markers are specific to CSCs is important as a high percentage of biomarkers are common to both CSCs and normal stem cells, which could lead to adverse effects [12]. In particular, some common antibody targets include CD44, EpCAM and ALDH [5,12,18]. As of date, a wide range of antibodies have been developed to target these biomarkers, with several therapeutics having reached clinical trials. For instance, an anti-Cd44 mAb, $\operatorname{Rg} 7356$, was tested in a phase 1 clinical study of acute myeloid leukemia patients and was shown to be well tolerated [20]. Similarly, an EpCAM antibody, Adecatumumb, was tested in patients with hormoneresistant prostate cancer, with great success [21]. However, while this targeting strategy has proven to be successful at eliminating target CSCs, biomarkers can vary between patients and even within tumours, and as such this type of 
UNDERGRADUATE RESEARCH IN NATURAL AND CLINICAL SCIENCE AND TECHNOLOGY (URNCST) JOURNAL Read more URNCST Journal articles and submit your own today at: https://www.urncst.com

drug might be most successful when combined with other therapeutic interventions [18].

\section{Transcriptional controls}

Some studies have demonstrated success with directly targeting the DNA of specific types of cancer cells. In liver cancer, histone deacetylase (HDAC) has been shown to enhance chemotherapy resistance [5]. In an in vivo study conducted by Zhang et al in 2010, HDAC inhibitors were used and resulted in suppression of leukemia stem cells [5]. Another transcriptional control, methyltransferase inhibitors, is under investigation for regulating gene transcription in cancer [5]. Genomic DNA is not uniformly methylated. There is extensive methylation in some areas, while other regions, such as the $\mathrm{CpG}$ islands within promoters, are hypomethylated [5]. In cancer, extensive de novo methylation is observed in the normally hypomethylated $\mathrm{CpG}$ islands, resulting in the silencing of tumour suppressor genes [5]. Recently, 3-deazaneplanocin A was proposed as a possible methyltransferase inhibitor to combat the extensive methylation in cancer cells [5].

\section{Quiescence}

Quiescence is the state in which a cell is inactive, which allows it to maintain the ability to enter the cell cycle at any time [5]. Cancer treatment strives to induce quiescent CSCs to proliferate, so that the cancer cell eventually undergoes apoptosis [5]. Essentially, if the ability of cells to enter and/or stay in quiescence is eliminated, the capacity for the non-specialized CSCs to evolve resistance is lowered [22]. Ishikawa et al reported that entry of leukemia stem cells into quiescence may be one of the mechanisms by which these cells resist chemotherapy [5]. They performed a global transcriptional profiling to identify leukemia stem cell-specific transcripts and concluded that leukemia stem cells maintained self-renewal capacity during chemotherapy-induced apoptosis [5]. Though no effective therapeutic to target quiescence has been found, this property is under research for novel therapeutic development.

\section{Microenvironment}

The CSC microenvironment provides a niche for the self-renewal and unspecialized properties of CSCs $[5,18]$. As such, drugs that disrupt these properties could be effective cancer therapeutics [5,9,12]. For example, the chemokine receptor CXCR4 has been noted as a key element in maintaining CSCs in their microenvironment [18]. Conversely, the inhibition of CXCR4 mobilizes CSC from their protective niche, increasing their sensitivity to other therapeutic treatments [18]. Thus, drugs that target CXCR4, such as plerixafor, could be used in combination with other cancer therapies, such as radiotherapy, to improve effectiveness [12,18]. Another potential target within the microenvironment are stromal cells, which physically shelter CSCs from pharmaceutical agents, and promote CSC growth and metastasis [5]. Lastly, targeting inflammatory cytokines such as IL-6 and IL-8 in the microenvironment could also be effective, as they similarly play a role in CSC self-renewal and metastasis [23]. Notably, targeting IL-8 through a non-competitive inhibitor, repertaxin, has been shown to decrease tumour size and increase the success of chemotherapy [23].

\section{Immunotherapy}

Tumour cells downregulate the normal functioning of the immune system by hyperactivating pathways that reduce the body's immune response, such as suppressing $\mathrm{T}$ cell inflammatory activity [18]. Novel CSC-related immunotherapy contributes to a healthier immune system to limit cancer progression and enhance self-protection [18] For one, tumour cells upregulate Programmed Cell Death (PD-1) pathway. PD-1 is an inhibitor protein of both adaptive and innate immune responses, and is expressed on activated $\mathrm{T}$, natural killer (NK) and B lymphocytes, macrophages, dendritic cells (DCs) and monocytes [24]. Most importantly, PD-1 is highly expressed on tumorspecific $\mathrm{T}$ cells, causing dilation of malignant cells by interfering with the protective immune response [24]. The antibody nivolumab was found to be effective in downregulating the PD-1 pathway to restore immune feedback balance. In addition, ipilimumab was identified as a novel antibody targeting CTLA-4 (cytotoxic Tlymphocyte-associated protein 4), an important receptor functioning as an immune checkpoint that downregulates immune responses [18]. The combined effect of nivolumab and ipilimumab showed positive results in improving the immunity of cancer patients [18].

\section{Discussion}

Using an integrative review approach, this study explored models for the genesis of functional heterogeneity within tumours and targeting strategies for CSCs. Specifically, the three most renowned models were discussed: hierarchy, stochastic and plasticity [1]. Though the mechanism for generating functional heterogeneity differed between models, CSC's ability to differentiate was consistently highlighted as a powerful barrier against treatment $[3,10,15]$. Therefore, the study also presents various targeting strategies to identify CSCs and destroy their "stemness" quality. Methods identified included those that target various cellular components such as signalling pathways, biomarkers, quiescence, microenvironment, transcriptional controls, and the immune system $[5,18]$. Many of these methods are still undergoing clinical trials, and as of yet an effective and universal treatment plan remains to be perfected.

Though three models were identified and discussed, it is uncertain which one, or if any, accurately represents the actual development and maintenance of cancer cells. This determination is complicated by the fact that different types of cancer might follow distinct models [1]. For example, 
UNDERGRADUATE RESEARCH IN NATURAL AND CLINICAL SCIENCE AND TECHNOLOGY (URNCST) JOURNAL Read more URNCST Journal articles and submit your own today at: https://www.urncst.com

the formation of tumours in breast cancer specifically has been shown to adhere to the plasticity model [25]. Moreover, each individual can have a distinct response, leading to variations in the same type of cancer among patients [1]. Hence, the scientific community should continue to explore the different types of heterogeneity models applicable to each type of cancer, and work towards developing efficient technologies to identify the cause of heterogeneity generation in cancer at an individual level.

The strength of this paper comes from the precisely defined search strategy, wide inclusion of databases and extensive scope of literature reviewed. Moreover, its integrative nature allows for the inclusion of a wide range of theoretical and empirical sources, allowing for a unique approach. However, at the same time the combination of the diverse methodologies used in the selected papers can lead to inaccuracy and bias as there is a lack of systematic methodology in synthesizing empirical evidence and theoretical reports. Furthermore, due to the lack of quality assessment of articles, it is not possible to adjust their weightings accordingly. In the future, more rigorous research methodologies should be used to identify gaps in the current literature.

Through this study, it was determined that a current critical gap in research is the fact that most experiments are conducted on mice or isolated cells, rather than on a tissue or human level. More clinical research is needed to better understand the effectiveness of CSC targeting strategies. Furthermore, more studies should be conducted to determine the optimal combination of the variety of new treatments being developed.

\section{Conclusions}

This study discusses in detail three models for the generation of functional heterogeneity among cancer cells, along with multiple methods of targeting CSCs. No specific model has been deemed as the correct pathway for heterogeneity generation in all cancer types, in fact, the model applicable may depend on the type of cancer $[1,5]$. Hence, the scientific community should continue testing models in the context of specific types of cancer. Nonetheless, CSCs are an integral part of tumour development and progression, thus, it is important to consolidate strategies to target their biomarkers, microenvironment, signalling pathways, transcription factors and develop immunotherapies [5].

\section{List of Abbreviations Used}

DNA: deoxyribonucleic acid

CSC: cancer stem cells

ZEB1: zinc finger E-box-binding homeobox 1

Hh: hedgehog pathway

GSI: y-secretase inhibitor

Wnt: wingless-related integration site pathway

NSAID: nonsteroidal anti-inflammatory drugs

siRNA: small interfering RNA

Lee et al. | URNCST Journal (2021): Volume 5, Issue 3

DOI Link: https://doi.org/10.26685/urncst.217
mAbs: monoclonal antibodies

EpCAM: epithelial cell adhesion molecule

ALDH: aldehyde dehydrogenases

HDAC: histone deacetylase

CXCR4: chemokine receptor type 4

IL-6 and IL-8: interleukin 6 and interleukin 8

CTLA-4: cytotoxic T-lymphocyte-associated protein 4

\section{Conflicts of Interest}

All authors declare that they have no conflict of interest.

\section{Ethics Approval and/or Participant Consent}

The study did not require ethics approval or participant consent. The paper is an integrative review of existent literature, hence no data collection involving human or animal participants was required.

\section{Authors' Contributions}

CX: Made substantial contribution to the conception/design of the work, and acquisition, analysis and interpretation of data for the work; drafted the work and revised it for important intellectual content; gave final approval for the version to be published; and agreed to be accountable for all aspects of the work in ensuring that questions related to the accuracy or integrity of any part of the work are appropriately investigated and resolved.

SGM: Made substantial contribution to the conception/design of the work, and acquisition, analysis and interpretation of data for the work; drafted the work and revised it for important intellectual content; gave final approval for the version to be published; and agreed to be accountable for all aspects of the work in ensuring that questions related to the accuracy or integrity of any part of the work are appropriately investigated and resolved.

JL: Made substantial contribution to the conception/design of the work, and acquisition, analysis and interpretation of data for the work; drafted the work and revised it for important intellectual content; gave final approval for the version to be published; and agreed to be accountable for all aspects of the work in ensuring that questions related to the accuracy or integrity of any part of the work are appropriately investigated and resolved.

\section{Acknowledgements}

We would like to acknowledge Jordan Donders for her help with editing and providing guidance for this paper.

\section{Funding}

This study was not funded.

\section{References}

[1] Meacham CE, Morrison SJ. Tumor heterogeneity and cancer cell plasticity. Nature. $2013 \quad$ Sep 19;501 (7467): 328-37. https://doi.org/10.1038/nature12624 
UNDERGRADUATE RESEARCH IN NATURAL AND CLINICAL SCIENCE AND TECHNOLOGY (URNCST) JOURNAL

Read more URNCST Journal articles and submit your own today at: https://www.urncst.com

[2] Dick JE. Stem cell concepts renew cancer research. Blood. 2008 Dec 15;112(13):4793-807. https://doi.org/ 10.1182/blood-2008-08-077941

[3] Rich JN. Cancer stem cells: understanding tumor hierarchy and heterogeneity. Medicine (Baltimore). 2016 Jan 8;95(Suppl1). https://doi.org/10.1097/ md.0000000000004764

[4] Tang DG. Understanding cancer stem cell heterogeneity and plasticity. Cell Res. 2012 Mar;22(3):457-72. https://doi.org/10.1038/cr.2012.13

[5] Dawood S, Austin L, Cristofanilli M. Cancer stem cells: implications for cancer therapy. Oncology (Williston Park). 2014 Dec;28(12):1101-7, 1110.

[6] M. Kroos J, Stinner C, Surulescu C, Surulescu N, ,Basque Center for Applied Mathematics, Alameda Mazarredo 14, 48009 Bilbao, Spain, ,Technische Universität Darmstadt, Schlossgartenstr. 7, 64289 Darmstadt, Germany, et al. SDE-driven modeling of phenotypically heterogeneous tumors: The influence of cancer cell stemness. Discrete \& Continuous Dynamical Systems - B. 2019;24(8):4629-63. http://dx.doi.org/10.3934/dcdsb.2019157

[7] Yuan S, Norgard RJ, Stanger BZ. Cellular Plasticity in Cancer. Cancer Discov. 2019 Jul;9(7):83751.https://doi.org/10.1158/2159-8290.cd-19-0015

[8] Bell JAH, Balneaves LG. Cancer patient decision making related to clinical trial participation: an integrative review with implications for patients' relational autonomy. Support Care Cancer. 2015 Apr;23(4):1169-96.https://doi.org/10.1007/s00520014-2581-9

[9] Heddleston JM, Hitomi M, Venere M, Flavahan WA, Yan K, Kim Y, et al. Glioma Stem Cell Maintenance: The Role of the Microenvironment. Curr Pharm Des. 2011;17(23):2386-401.

https://doi.org/10.2174/138161211797249260

[10] Sousa B, Ribeiro AS, Paredes J. Heterogeneity and Plasticity of Breast Cancer Stem Cells. In: Birbrair A, editor. Stem Cells Heterogeneity in Cancer [Internet]. Cham: Springer International Publishing; 2019 [cited 2020 Nov 2]. p. 83-103. (Advances in Experimental Medicine and Biology). Available from: https://doi.org/10.1007/978-3-030-14366-4_5

[11] Cabrera MC, Hollingsworth RE, Hurt EM. Cancer stem cell plasticity and tumor hierarchy. World Journal of Stem Cells. 2015 Jan 26;7(1):27-36. https://doi.org/ 10.4252/wjsc.v7.i1.27

[12] Saygin C, Matei D, Majeti R, Reizes O, Lathia JD. Targeting Cancer Stemness in the Clinic: From Hype to Hope. Cell Stem Cell. 2019 Jan 3;24(1):25-40. https://doi.org/10.1016/j.stem.2018.11.017

[13] Visvader JE, Lindeman GJ. Cancer Stem Cells: Current Status and Evolving Complexities. Cell Stem Cell. 2012 Jun 14;10(6):717-28. https://doi.org/10.1016/j.stem .2012 .05 .007

Lee et al. | URNCST Journal (2021): Volume 5, Issue 3

DOI Link: https://doi.org/10.26685/urncst.217
[14] Nowell P. The clonal evolution of tumor cell populations. Science. 1976 Oct 1;194(4260):23-8. https://doi.org/10.1126/science. 959840

[15] Tabarestani S, Ghafouri-Fard S. Cancer Stem Cells and Response to Therapy. Asian Pacific Journal of Cancer Prevention. 2012;13(12):5947-54. http://dx.doi.org/ 10.7314/APJCP.2012.13.12.5947

[16] Schiffer D, Annovazzi L, Casalone C, Corona C, Mellai M. Glioblastoma: Microenvironment and Niche Concept. Cancers (Basel). 2018 Dec 20;11(1). https://dx.doi.org/10.3390\%2Fcancers11010005

[17] Doherty MR, Smigiel JM, Junk DJ, Jackson MW. Cancer Stem Cell Plasticity Drives Therapeutic Resistance. Cancers (Basel). 2016 Jan 5;8(1). https://doi.org/10.3390/cancers8010008

[18] Yang L, Shi P, Zhao G, Xu J, Peng W, Zhang J, et al. Targeting cancer stem cell pathways for cancer therapy. Sig Transduct Target Ther. 2020 Dec;5(1):8. https://doi.org/10.1038/s41392-020-0110-5

[19] Walcher L, Kistenmacher A-K, Suo H, Kitte R, Dluczek S, Strauß A, et al. Cancer Stem CellsOrigins and Biomarkers: Perspectives for Targeted Personalized Therapies. Front Immunol. 2020 Aug 7;11:1280. https://doi.org/10.3389/fimmu.2020.01280

[20] Menke-van der Houven van Oordt CW, Gomez-Roca C, van Herpen C, Coveler AL, Mahalingam D, Verheul HMW, et al. First-in-human phase I clinical trial of RG7356, an anti-CD44 humanized antibody, in patients with advanced, CD44-expressing solid tumors. Oncotarget. 2016 Aug 5;7(48):80046-58. https://doi.org/10.18632/oncotarget.11098

[21] Oberneder R, Weckermann D, Ebner B, Quadt C, Kirchinger $\mathrm{P}$, Raum $\mathrm{T}$, et al. A phase I study with adecatumumab, a human antibody directed against epithelial cell adhesion molecule, in hormone refractory prostate cancer patients. Eur J Cancer. 2006 Oct;42(15):2530-8. https://doi.org/10.1016/j.ejca.2006 .05 .029

[22] Davis JE, Kirk J, Ji Y, Tang DG. Tumor Dormancy and Slow-Cycling Cancer Cells. Adv Exp Med Biol. 2019;1164:199-206. https://doi.org/10.1007/978-3030-22254-3_15

[23] Casilli F, Bianchini A, Gloaguen I, Biordi L, Alesse E, Festuccia $\mathrm{C}$, et al. Inhibition of interleukin-8 (CXCL8/IL-8) responses by repertaxin, a new inhibitor of the chemokine receptors CXCR1 and CXCR2. Biochem Pharmacol. 2005 Feb 1;69(3):385-94. https://doi.org/10.1016/j.bcp.2004.10.007

[24] Han Y, Liu D, Li L. PD-1/PD-L1 pathway: current researches in cancer. Am J Cancer Res. 2020 Mar 1;10(3):727-42.

[25] Yang T, Rycaj K. Targeted therapy against cancer stem cells (Review). Oncology Letters. 2015 Jul 1;10 (1):27-33. https://dx.doi.org/10.3892\%2Fol.2015.3172 
UNDERGRADUATE RESEARCH IN NATURAL AND CLINICAL SCIENCE AND TECHNOLOGY (URNCST) JOURNAL

Read more URNCST Journal articles and submit your own today at: https://www.urncst.com

\section{Article Information}

Managing Editor: Jeremy Y. Ng

Peer Reviewers: Jordan Donders, Siobhan O'Brien

Article Dates: Received Nov 11 20; Accepted Feb 25 21; Published Mar 2621

\section{Citation}

Please cite this article as follows:

Lee J, Metla SG, Xu C. Models of functional heterogeneity and targeting strategies for cancer stem cells. URNCST Journal.

2021 Mar 26: 5(3). https://urncst.com/index.php/urncst/article/view/217

DOI Link: https://doi.org/10.26685/urncst.217

\section{Copyright}

(C) Joan Lee, Sai Gayathri Metla, Chaoqun Xu. (2021). Published first in the Undergraduate Research in Natural and Clinical Science and Technology (URNCST) Journal. This is an open access article distributed under the terms of the Creative Commons Attribution License (https://creativecommons.org/licenses/by/4.0/), which permits unrestricted use, distribution, and reproduction in any medium, provided the original work, first published in the Undergraduate Research in Natural and Clinical Science and Technology (URNCST) Journal, is properly cited. The complete bibliographic information, a link to the original publication on http://www.urncst.com, as well as this copyright and license information must be included.

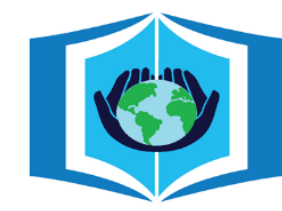

\section{URNCST Journal}

"Research in Earnest"

\section{Funded by the \\ Government \\ of Canada}

\section{Canadà̀}

Do you research in earnest? Submit your next undergraduate research article to the URNCST Journal!

|Open Access | Peer-Reviewed | Rapid Turnaround Time | International |

| Broad and Multidisciplinary | Indexed | Innovative | Social Media Promoted |

Pre-submission inquiries? Send us an email at info@ urncst.com |Facebook, Twitter and LinkedIn: @ URNCST

Submit YOUR manuscript today at https://www.urncst.com! 